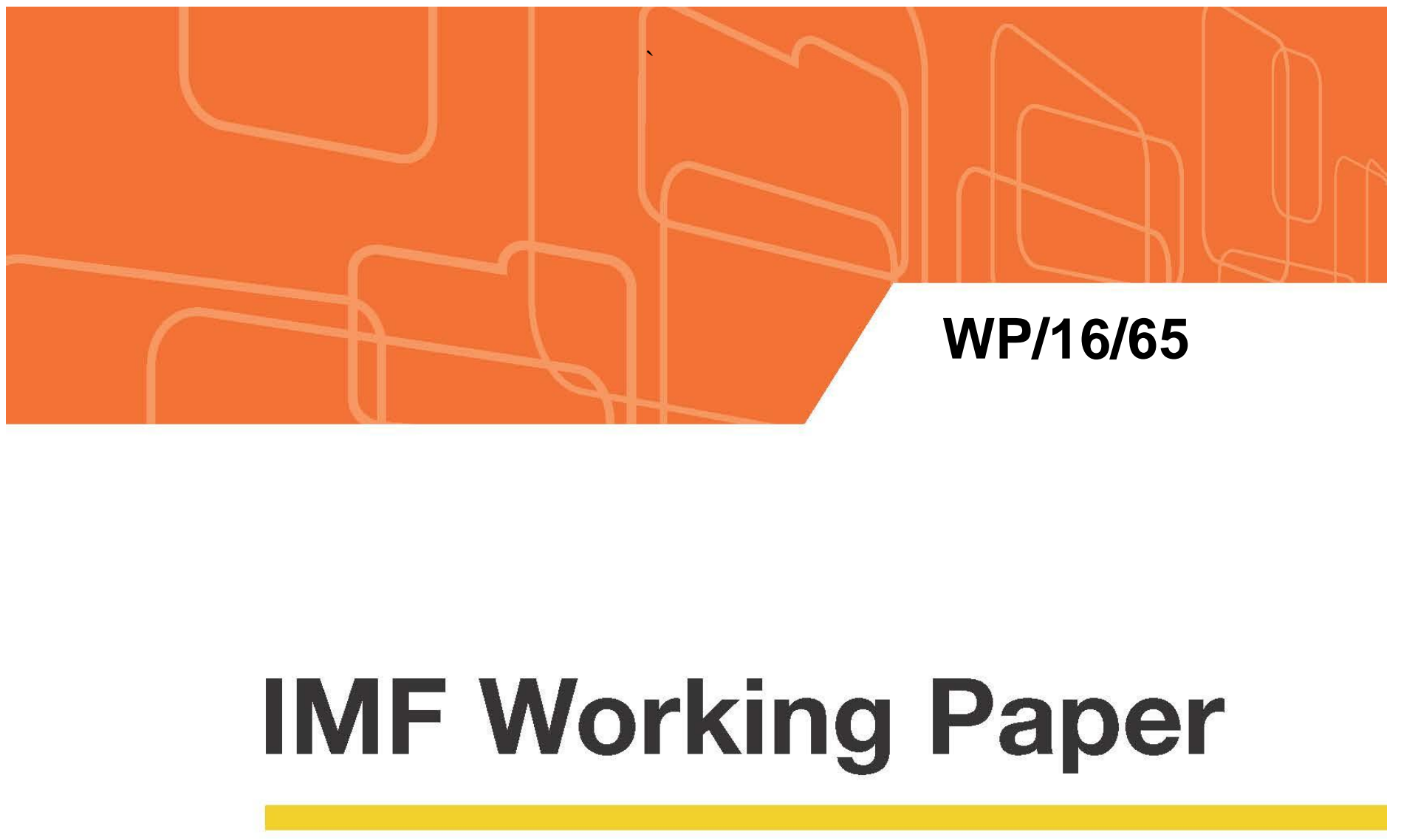

\title{
Natural Disasters and Food Crises in Low- Income Countries: Macroeconomic Dimensions
}

By Olumuyiwa S. Adedeji, Jana Gieck-Bricco, and Vera Kehayova 


\title{
IMF Working Paper
}

Strategy, Policy, and Review Department

\section{Natural Disasters and Food Crises in Low-Income Countries: Macroeconomic Dimensions}

\author{
Prepared by Olumuyiwa S. Adedeji, Jana Gieck Bricco, and Vera Kehayova ${ }^{1}$ \\ Authorized for distribution by Chris Lane
}

March 2016

\section{IMF Working Papers describe research in progress by the author(s) and are published to elicit comments and to encourage debate. The views expressed in IMF Working Papers are those of the author(s) and do not necessarily represent the views of the IMF, its Executive Board, or IMF management.}

\begin{abstract}
The exposure of low-income countries to natural disasters has a significant impact on food production and food security. This paper provides a framework for assessing a country's vulnerability to food crisis in the event of natural disasters. The paper finds that macroeconomic and structural indicators that are crucial for ensuring the resilience of lowincome countries to adverse external shocks are equally important for minimizing the occurrence of food crisis in the event of natural disasters.

JEL Classification Numbers: C25, E32, O11, F 43.

Keywords: Natural disasters, Food decline

Author’s E-Mail Address: oadedeji@imf.org, jgieck@imf.org,vera_kehayova@yahoo.com

\footnotetext{
${ }^{1}$ This paper benefitted from the comments of Rabah Arezki, Manoj Atolia, Yasemin Bal Gündüz,Kerstin Gerling, Burcu Hacibedel, Henry Mooney, Dongyeol Lee, Patrizia Tumbarello, Marina Rousset, and Olaf Unteroberdoerster. Zhe Liu and Corinne Stephenson provided outstanding research assistance.
} 
I. INTRODUCTION

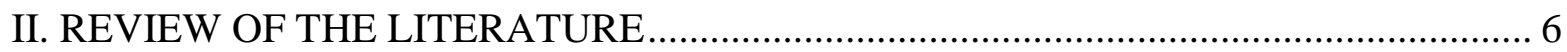

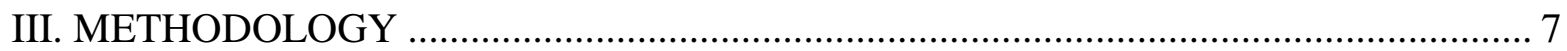

A. Identification of Large Natural Disasters ............................................................... 7

B. Identification of the Dependent Variable: Food Crisis ................................................. 7

IV. EMPIRICAL ANALYSIS: ECONOMETRIC FRAMEWORK ….................................... 8

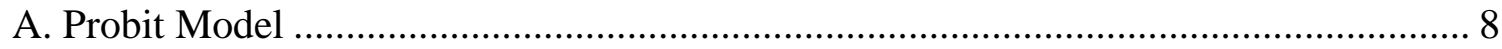

B. Estimation Results: Benchmark Probit Specifications .............................................. 10

C. Goodness of Fit of Probit Model........................................................................... 13

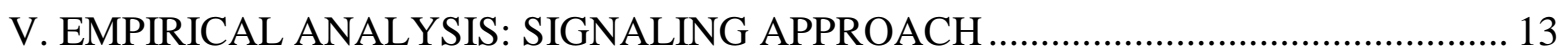

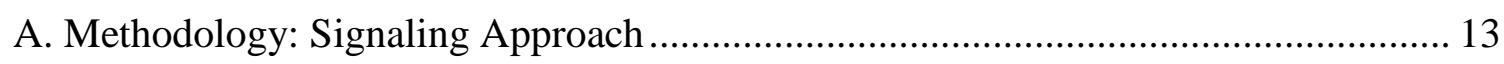

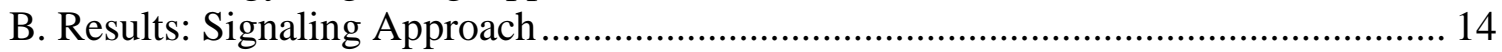

C. Goodness of Fit of Signaling Approach ................................................................ 16

D. Assessment of Vulnerabilities since 1990s................................................................. 17

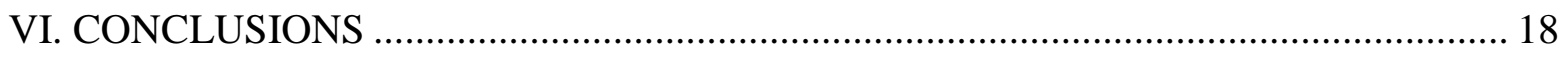

Figures

1. Identification of Natural Disaster Episodes

2. Distribution of Food Supply Per Capita Growth: Food Crisis Versus Normal Episodes, 1990-2009:

3. Food Decline Vulnerability Index

4. Natural Disasters and People Affected

5. Food Decline Vulnerability Index by Sub-Group

Tables

1. Median of Food Supply Per capita Growth, 1990-2009 .................................................. 7

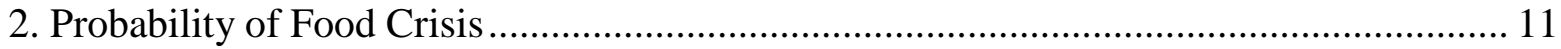

3. Benchmark Regression: Average and Conditional Marginal Effects ................................. 12

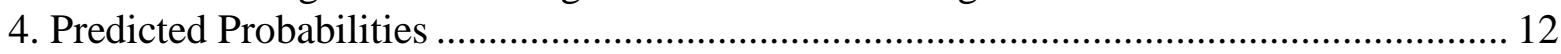

5. Food Decline Vulnerability Index Estimation Results ................................................... 15

6. Distribution of Predicted Probabilities: Vulnerability Index Versus Its Sub-Components 16

7. Distribution of Food Decline Vulnerability Index: Percentiles .......................................... 16

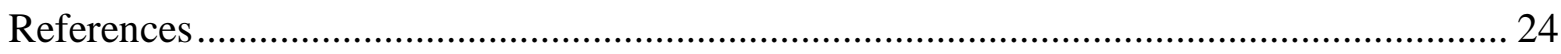




\section{INTRODUCTION}

The frequency of natural disasters in low-income countries (LICs) has increased over time and is expected to increase further with global warming (World Bank (2014) and IMF $(2014)) .^{2}$ However, poor infrastructure and scarce resources in LICs limit their capacity to withstand natural disasters. In addition, their economies are generally less diversified, thereby reducing post-shock economic resilience (Laframboise and Loko, 2012). ${ }^{3}$ At a micro level, natural disasters are likely to have a higher impact on the poorest, given their limited capacity to respond (e.g., via savings and access to credit—see Hallegate and Przyluski, 2010).

LICs' exposure to natural disasters can have a significant impact on food production and food crisis, the focus of the current paper. Nearly a quarter of damages wrought by natural disasters on LICs are borne by the agricultural sector (FAO, 2015). In this connection, an understanding of the interplay between the occurrence and the impact of natural disaster on food crises and how the availability of macroeconomic buffers could help to mitigate the impact of such shocks is important. Nonetheless, there has been limited analysis on the role that strong macroeconomic position could potentially play in reducing the vulnerability of LICs to a food crisis. Natural disasters tend to affect domestic production of food and could potentially lead to food crises in the absence of strong macroeconomic positions. Large scale natural disasters often disrupt, if not destroy domestic production. They tend to not only reduce short-term domestic food production, but pose a major risk to future production. Reduced domestic production could be supplemented by imports in the presence of strong external and fiscal positions, thereby avoiding food crisis. While external food assistance could be important, such as the world food program, it has turned out to be insufficient in the context of significant natural disasters. In addition, to protect the poor from the high food prices, occasioned by natural disasters or global developments, governments had adopted a variety of fiscal instrument such as higher subsidies, lower food taxes and tariffs, and scaledup public transfers. The ability of a government to carry out such policy measures would reflect pre-existing fiscal position. In this connection, this paper aims to answer the following specific questions: (i) do natural disasters matter for food crises? and (ii) could strong macroeconomic conditions help to limit the occurrence of natural disasters from evolving into food crises?

A number of existing studies provide the analytical basis for the current paper. Food crisis is perceived in the literature as the probability of an acute decline in food access or

\footnotetext{
${ }^{2}$ Appendix I provides a list of 55 LICs covered in this paper, which were all drawn from the list of PRGTeligible countries.

${ }^{3}$ Natural disaster data come from the Emergency Events Database (EM-DAT) managed by the Centre for Research on the Epidemiology of Disasters (CRED). They comprise geophysical (earthquake), metereological (storms), hydrological (floods), climatological (droughts), and biological (epidemics) incidents. A disaster is registered in the database (occurrence of natural disaster) if one of the following conditions is met: (i) 10 or more fatalities; (ii) 100 or more people "affected;" (iii) a call for international assistance; and (iv) the declaration of a state of emergency. People "affected" by a disaster include those injured, homeless/displaced, or requiring immediate assistance, but exclude fatalities.
} 
consumption often in reference to some critical value. ${ }^{4}$ The ensuing vulnerability depends on exposure to shocks and underlying socio-economic variables (Chambers (1989) and Riely (2000)). Similar to the concept of a growth crisis (see Dabla-Norris and Bal Gündüz (2012 and 2014)), ${ }^{5}$ the current paper places emphasis on severe decline in food availability on the basis of which a food crisis episode is identified. Our measures of food availability encompasses the "total quantity of foodstuffs produced in a country added to the total quantity imported and adjusted for any change in stocks that may have occurred since the beginning of the reference period. ${ }^{6}$

Multivariate regression analysis and a univariate 'signaling' approach are used to map information from the underlying indicators to form a composite food crisis index. The former method adopts a correlated probit model to determine the probability of a food crisis, which allows correlations among variables, to determine the significance of individual variable, and to ascertain the constancy of coefficients across country groups. The univariate signaling approach involves the use of each indicator to determine food crises separately, thereby identifying thresholds that signal such events with the lowest prediction error, and then averaging the indicators in a summary index. These two approaches are complementary, as the results from the probit analysis guide the selection of variables used in the univariate approach.

This paper develops a food crisis index (FCI) to assess the vulnerability of LICs to food crisis due to the occurrence of natural disasters, focusing on macroeconomic (mainly external and fiscal indicators) and institutional indicators. Results show that the probability of experiencing a food crisis increases for countries with weaker institutions and low food production fundamentals measured by food supply per capita growth trend. Sound policy fundamentals such as low fiscal deficit and high reserve coverage are linked to a lower likelihood of food crisis. The constructed index can be used to assess vulnerabilities to food crisis in LICs over time.

The rest of the paper is organized as follows: Section II presents a succinct review of the literature. Section III provides the methodology underlying the paper. Section IV presents empirical analysis, focusing on probit estimation. Section V presents empirical results from the use of signaling approach. Section VI concludes the paper.

\footnotetext{
${ }^{4}$ Much remains to be achieved, both in terms of data quality and coverage and regarding methods, standards and tool for assessing for food security (Cafiero, 2013). In addition, this paper has not dealt with all issues that could potentially impact on the occurrence of food crisis. For example, a grain reserve management framework could help to avert food crisis in the event of a natural disaster. A permanent regional cooperation mechanism for managing food reserves could serve as insurance in times of food crises (Arezki and others, 2012).

${ }^{5}$ The basic approach draws on the methodology for the growth decline vulnerability index (GDVI). The GDVI measures a country's vulnerability to sudden growth declines in the event of a large exogenous shock. A range of indicators is examined to identify variables and thresholds to separate crisis from non-crisis cases. For details on the GDVI, see Dabla-Norris and Bal Gündüz (2012 and 2014).

${ }^{6}$ It is based on the database of the Food and Agriculture Organization (FAO) of the United Nations.
} 


\section{REVIEW OF THE LITERATURE}

The starting point for our work is empirical methods used in the papers that examined the relationship between the occurrence of natural disasters and overall growth. ${ }^{7}$ While most studies use classical regression analysis, Cavallo and others (2010) employ synthetic control methods, and a vast literature uses descriptive case studies. Cavallo and others (2010) found that only extremely large disasters have a negative effect on output both in the short and long term. Skidmore and Toya (2005) found that countries with higher incomes, higher educational attainments, greater openness, more complete financial systems and smaller governments, experience fewer losses from natural disasters.

This paper builds on existing studies that examined the impact of natural disasters on agriculture, focusing primarily on food crises. Some studies provide conceptual framework for analyzing a country's vulnerability to food crisis and potential indicators that could help enhance resilience (Capaldo and others (2010); Burg (2008); and Lucas and Hilderink (2004)). Other studies have adopted empirical methods to analyze the same issue. Loayza and others (2009) found that in contrast to the weak effects on overall GDP growth, droughts and storms have negative impacts on agriculture, while floods have a positive effect. Sivakumar (2005) explained that the predominant impacts of natural disasters on agriculture are negative. Long (1978) argued that the negative effects of disasters are a powerful partial explanation of the lack of agricultural self-sufficiency in a large number of LICs. The Economist Intelligence Unit (2013) has also created a global food security index, with categories and indicators selected on the basis of expert analysis and consultation with a panel of food security specialists, but covering only about half of the countries in the current paper.

An assessment of food crisis requires paying particular attention to fragile states. Food crisis could potentially increase the risk of conflict (World Bank, 2011). A majority of fragile states are food importers. Fragile institutions and poor governance help explain why similar external shocks can produce violence in one country but not in another. Developing countries with low government effectiveness experienced more food price protests during the food crisis (2007-08) than countries with high government effectiveness (World Bank, 2011).

This paper, however, brings to sharper focus on the link between natural disasters and food crisis episodes. A quantitative assessment of the relative importance that macroeconomic and institutional factors could play in averting food crisis in the context of natural disasters constitutes a novel perspective in the current paper. The constructed index could usefully serve as an early warning indicator, identifying countries that are vulnerable to food crisis. The availability of such index could help with putting in place appropriate macroeconomic policy response and targeted interventions to avoid food crisis and the attendant economic and humanitarian costs.

\footnotetext{
${ }^{7}$ The immediate destruction associated with natural disasters could cause a number of adverse socio-economic consequences. They may also have growth-improving effects as investment for construction is part of measured gross domestic product, whereas the destruction of physical capital is not.
} 


\section{Methodology}

\section{A. Identification of Large Natural Disasters}

Large natural disasters shocks are identified if their impact on the economy is above the norm. Specifically, if the cost of damages in percent of GDP and/or the amount of people affected in percent of the population is above the 50th percentile (i.e., in the right-tail) of the country-specific distribution. Each natural disaster shock is considered only in the first year of its occurrence, resulting in a total of 166 shocks (out of 989 observations).

Comparing the average of people affected and the cost of damages caused by a natural disaster for the upper percentile of the distribution (Figure 1), the ratio of people affected by natural disasters in shock episodes, that is natural disasters above the $50^{\text {th }}$ percentile, is much larger than in non-shock episodes. This suggests that our shock cut-off captures

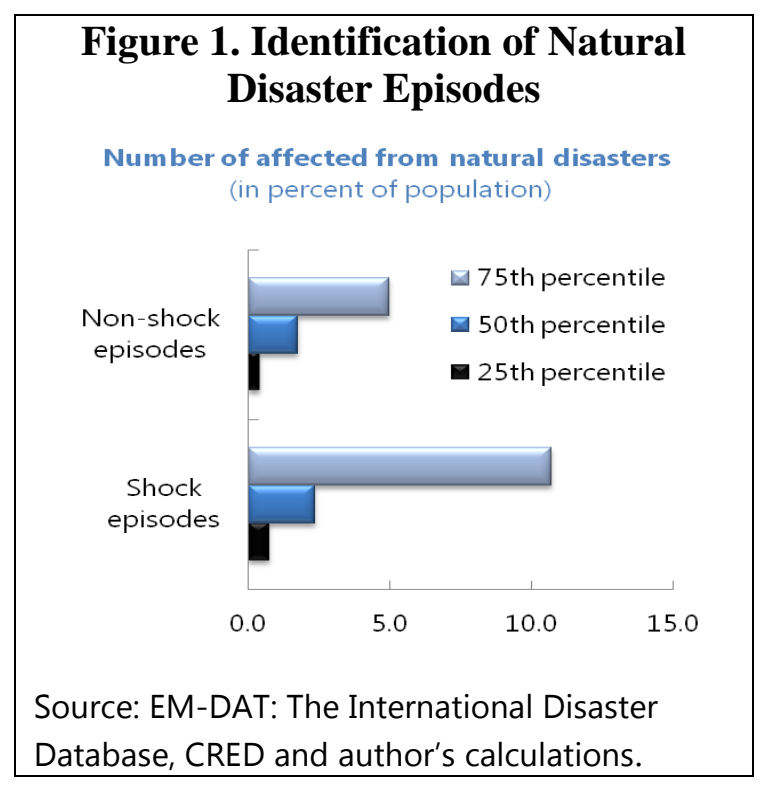
reasonably well severe natural disaster shocks.

\section{B. Identification of the Dependent Variable: Food Crisis}

A food crisis is defined as a large drop in daily food supply (crops and livestock) measured in kilocalories per capita. A food crisis occurs when the following two conditions hold: (i) the two year average level of daily food supply per capita after the shock $(t$ and $t+1)$ falls below the pre-shock three-year average; and (ii) year-on-year growth of food supply per capita is negative at time $t$. All other observations that do not meet these criteria are considered as normal

Table 1. Median of Food Supply Per Capita Growth (1990-2009)

\begin{tabular}{lllll}
\hline & All & Food & Normal & $\begin{array}{l}\text { Sample } \\
\text { Probability } \\
\text { Median }\end{array}$ \\
\cline { 2 - 5 } Episodes & Crisis & Episodes & of Crisis \\
\hline Observations & 0.63 & -2.52 & 1.22 & 0.25 \\
\hline
\end{tabular}

Source: FAO and author's calculations. episodes. This definition of a food crisis follows the example of a growth crisis as in DablaNorris and Bal Gündüz (2012 and 2014). This definition identifies severe food crisis events, which not only lead to a negative food supply growth but also alter the level of food supply such that the following two years after the event were substantially below the previous three years. This definition ensures that we are not capturing small one-off events leading to a "random" decline in food supply but serious shocks. In a second step, we match food crises to severe natural disasters. The data span 55 LICs during 1990-2009 period, yielding 1,180 observations. However, the sample shrinks to 45-47 countries, depending on data availability 
in various estimations. We identify 218 food crisis episodes, but only 42 of these coincide with large natural disaster episodes as defined below.

Table 1 shows the median growth rate of food supply per capita for the sample coinciding with natural disaster shocks and distinguishes between food crisis and non-food crisis episodes. The positive median growth number for the overall sample means that not all natural disasters cause a decline in food supply. This is explained by the low probability of a food supply decline within the shock sample of 25 percent. Nevertheless, we observe a statistically significant difference in food supply growth per capita of more than 3.74 percentage points between crisis and non-crisis episodes.

Figure 2 presents the distribution of food supply per capita for crisis and non-crisis episodes. In many cases, the drop in food supply growth (negative value) is also associated with a persistent

Figure 2. Distribution of Food Supply Per Capita Growth: Food Crisis Versus Normal Episodes (1990-2009)

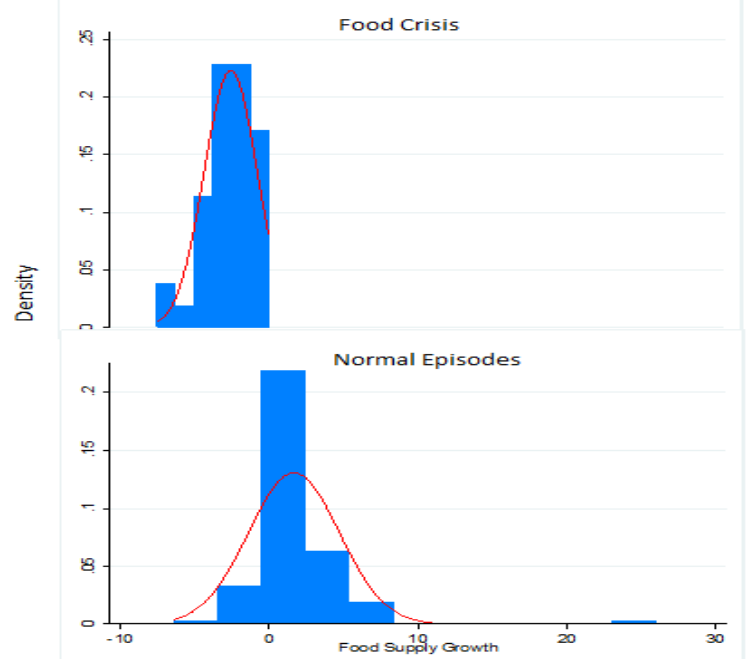

Source: FAO and authors' calculations.

decline in the level of food supply. This means, that once food supply growth is negative, food supply declines tend to be persistent, there is no quick recovery, a key vulnerability in LICs.

\section{Empirical ANALysis: Econometric Framework}

\section{A. Probit Model}

To estimate the effect of various macroeconomic and institutional variables on the likelihood of a food crisis coinciding with a large natural disaster, we apply a binary response model for panel data. By conditioning food crisis episodes on natural disasters, we identify the determinants of the food supply crisis. The panel probit model used in this analysis is specified as:

$y_{i t}=1 \quad$ food crisis

$y_{i t}=0 \quad$ normal episodes

$P\left(y_{i t}=1 \mid x_{i t}, c_{i}\right)=\Phi\left(x_{i t}^{\prime} \beta+c_{i}\right) i=1, \ldots, n$ and $t=1, \ldots, T$

with $y_{i t}$ the observed outcome of a crisis state, $\Phi$ is the cumulative normal density function, $x_{i t}$ is the $1 x k$ vector of explanatory variables, and $\beta$ is the $k x 1$ vector of coefficients 
associated with $x_{i t}$. We estimated the model step-by-step using fixed effect, random effect and the Chamberlain (1982)-Mundlak (1978) (CM) approach, which is a mixture of the two. ${ }^{8}$ Fixed effects estimator was rejected, as expected, while the random effect estimator and the $\mathrm{CM}$ approach was not. While the results of the random effects estimator and CM approach are broadly the same (similar signs and coefficients), ${ }^{9}$ we adopted the CM estimator as it performed better in our estimations. Further, it is more likely that the unobserved country specific variable $c_{i}$ is correlated with the explanatory variables $x_{i}$ as unobserved country specific effects are likely to affect Country Policy and Institutional Assessment (CPIA), fiscal balance, reserve coverage, and exchange market pressure index and vice versa.

In line with the literature, we start with a set of 22 potential variables that could explain food crisis (see Appendix Table 3). A general-to-specific approach points to narrowing significant indicators to seven variables: These variables are discussed below:

- Policy and external variables: These include the ratio of government balance to GDP, reserve coverage (in months of imports of goods and services), and the exchange market pressure index. The latter is a composite index comprising depreciation of the official exchange rate, change in the stock of international reserves (in months of imports of goods and services), and the parallel market premium. The fiscal and external indicators reflect the role of macroeconomic buffers in limiting food crisis. Weaker fiscal positions and limited external reserves could have negative implications for food availability, not the least of which is the constrained ability to import food. The inclusion of change in export prices and growth in trading partners (weighted by lagged exports to GDP) is meant to capture possible vulnerability to trade-related shocks and the associated impact on income earnings.

- $\quad$ Structural and institutional variable (two indicators): These include the World Bank's CPIA ${ }^{10}$, and the country-specific average of food supply per capita growth over the sample period (measured in kilo calories). The latter is an approximation for cross-country differences in underlying structural and institutional conditions, capturing shock amplifiers such as efficiency of food production and importation, distribution, and marketing. The quality of institution could be important for averting a food crisis that could potentially arise from the occurrence of natural disasters. Weak institutions could entail poor administrative quality, leading to inability to

\footnotetext{
${ }^{8} \mathrm{~A}$ random effects (RE) probit model treats the individual specific effect, $c_{i}$, as an unobserved random variable with $c_{i} \mid x_{i t} \sim I N\left(\mu_{c}, \sigma_{c}\right)$ if an overall intercept is excluded, and imposes independence of $c_{i}$, and $x_{i t}$. A fixed effects (FE) probit model treats $c_{i}$ as parameters to be estimated along with $x_{i t}$., and does not make any assumptions about the distribution of $c_{i}$ given $x_{i t}$. In short panels, this can be problematic as both $c_{i}$, and $x_{i t}$. are inconsistently estimated owing to an incidental parameters problem. Finally, a correlated model relaxes independence between $c_{i}$ and $x_{i t}$ using the Chamberlain (1982)-Mundlak (1978) device under conditional normality. In this specification, the time average is often used to save on degrees of freedom.

${ }^{9}$ Results are available upon request.

${ }^{10}$ The World Bank's CPIA is a broad indicator of the quality of a country's present policy and institutional framework. It is based on 16 criteria which are grouped into four clusters: economic management, structural policies, policy for social inclusion and equity, and public sector management and institutions.
} 
ensure that regions with food shortage in the context of a natural disaster have adequate access to food in a timely fashion.

All explanatory variables are lagged by one year, except for the variables capturing exogenous shocks, and are thus predetermined with respect to the crisis event.

\section{B. Estimation Results: Benchmark Probit Specifications}

Table 2 presents the estimation results of the probit regressions for all 55 LICs (Column 1) and for LICs excluding fragile states. ${ }^{11} \mathrm{We}$ ascertain if the empirical results differ between fragile and non-fragile states, as the challenge of food crisis is likely to be more pronounced in the former due to weaker institutional framework and comparatively lower macroeconomic buffers.

Results show the probability of experiencing a food crisis increases for countries with weaker institutions (proxied by CPIA) and low food supply per capita growth trend. Sound policy fundamentals such as a high fiscal balance and reserve coverage are linked to a lower likelihood of food crisis. An increase in exchange market pressure index tends to reduce the probability of food supply crisis. This suggests that exchange rate depreciation and lower international reserves tend to encourage domestic food production, leading to higher exports and income. Positive shocks which increase growth in trading partners decrease the probability of a food crisis, while high export prices increase the probability of such crisis. The latter result could suggest that high export prices tends to be associated with a shift in food supply from domestic to external markets, as return margins are higher due to high export prices. To identify the intensity of natural disasters to cause a food crisis, we add the variable "people affected from natural disaster," which we also use to identify the dummy variable "natural disaster shocks," to the regression (Column 2). While the impact is as expected - the more people are affected by a natural disaster, the higher the probability of a food crisis - the variable, though is not statistically significant. When excluding fragile states (Column 3), CPIA, fiscal balance, and EMPI become insignificant. This seems to suggest that these variables are important mostly for fragile states, indicating that improving institutional frameworks and macroeconomic buffers would be critical to reducing food crisis episodes in this group of countries. Finally, we also estimate the model using a logit approach (Colum 4) and the empirical results are almost identical. It is reassuring that the logit identifies the same variables as significant determinants of food crises as the probit.

\footnotetext{
${ }^{11}$ Fragile states are countries classified as having either weak institutional capacity measured by the World Bank's CPIA score (average of 3.2 or lower) and/or experience of conflict (signaled by presence of a peacekeeping or peace-building operation in the most recent three-year period). This approach is similar to that used by the World Bank and the African Development Bank, differing only in using a three-year average of the CPIA instead of the most recent outturn. Other organizations, using slightly different metrics, define a larger number of countries as fragile (for instance, 50 countries are defined as fragile in the OECD's 2015 States of Fragility Report).
} 
Table 2. Probability of Food Crisis

\begin{tabular}{|c|c|c|c|c|}
\hline & $\begin{array}{l}\text { All LICs } \\
\text { (1) }\end{array}$ & $\begin{array}{c}\text { With People } \\
\text { Affected } \\
(2)\end{array}$ & $\begin{array}{c}\text { Excluding } \\
\text { Fragile States } \\
\text { (3) }\end{array}$ & $\begin{array}{l}\text { All LICs } \\
\text { Logit } \\
(4)\end{array}$ \\
\hline \multirow[t]{2}{*}{ CPIA (t-1) } & $-0.584^{*}$ & $-0.683^{\star}$ & -0.235 & $-0.964^{*}$ \\
\hline & $(0.265)$ & $(0.304)$ & $(-0.451)$ & $(0.489)$ \\
\hline \multirow[t]{2}{*}{ Government balance, (\% of GDP) ( $t-1)$} & $-0.0431^{*}$ & $-0.0405^{\star}$ & 0.016 & $-0.0714^{*}$ \\
\hline & $(0.0199)$ & $(0.0199)$ & $(-0.028)$ & $(0.0357)$ \\
\hline \multirow[t]{2}{*}{ Food supply growth average (cal) } & $-1.090^{\star * *}$ & $0.131^{\star * *}$ & $-1.36^{\star * *}$ & $0.180^{\star * *}$ \\
\hline & $(0.234)$ & $(0.0336)$ & $(0.348)$ & $(0.0529)$ \\
\hline \multirow[t]{2}{*}{ Reserve coverage (months of imports) ( $t-1$ ) } & $-0.153^{*}$ & $-0.781^{\star \star}$ & $-0.291^{\star \star \star}$ & $-0.970^{\star *}$ \\
\hline & $(0.0623)$ & $(0.263)$ & $(0.102)$ & $(0.337)$ \\
\hline \multirow[t]{2}{*}{ Export prices percent change } & $0.105^{\star \star \star}$ & $-1.213^{\star \star \star}$ & $0.165^{\star \star \star}$ & $-1.819 * * *$ \\
\hline & $(0.0315)$ & $(0.286)$ & $(0.053)$ & $(0.409)$ \\
\hline \multicolumn{5}{|l|}{ Growth in trading partners weighted by lagged } \\
\hline \multirow[t]{2}{*}{ exports to GDP } & $-0.552^{\star \star}$ & $-0.222^{\star \star}$ & $-0.525^{\star *}$ & $-0.272^{*}$ \\
\hline & $(0.185)$ & $(0.0745)$ & $(0.235)$ & $(0.112)$ \\
\hline \multirow[t]{2}{*}{ Exchange market pressure index } & $-0.135^{\star}$ & $-0.200^{\star}$ & -0.113 & $-0.233^{*}$ \\
\hline & $(0.0584)$ & $(0.0912)$ & $(-0.093)$ & $(0.116)$ \\
\hline \multirow{3}{*}{$\begin{array}{l}\text { People affected from natural disasters (in } \\
\text { percent of population) }\end{array}$} & & & & \\
\hline & & 0.00685 & & \\
\hline & & $(0.0220)$ & & \\
\hline \multirow[t]{2}{*}{ Constant } & $2.364^{*}$ & $3.089 * *$ & 1.742 & $3.975^{\star}$ \\
\hline & $(1.001)$ & $(1.179)$ & $(-1.654)$ & $(1.784)$ \\
\hline Observations & 129 & 108 & 82 & 129 \\
\hline Pseudo R-sq & 0.266 & 0.324 & 0.371 & 0.261 \\
\hline Number of countries & 45 & 45 & 29 & 45 \\
\hline Food decline episodes & 28 & 24 & 15 & 28 \\
\hline Normal episodes & 101 & 84 & 67 & 101 \\
\hline Wald test (Chi-square) & 39.26 & 33.99 & 39.15 & 36.72 \\
\hline Sample probability & 0.22 & 0.22 & 0.18 & 0.22 \\
\hline
\end{tabular}

Due to the non-linearity of the model, coefficients shown in Table 2 cannot be interpreted directly. Therefore, we estimate marginal effect to present the relative impact of each variable (see Table 3). The estimated coefficients highlight the relative importance of each variable on the likelihood of a food crisis. In Table 3, we show the average marginal effects for the average, median and weak performing country as represented by countries in the lower quartiles of the distribution. According to these results, structural variables such as average food supply per capita and CPIA predict best a food crisis. Furthermore, these variables gain even more prominence for countries with weaker macroeconomic and structural fundamentals (column 3) when compared to the median country (column 2). This suggests that improvements in structural fundamentals related to the production of food 
supply as well as the quality of a countries policy and institutional framework would contribute substantially to reducing vulnerability to a food crisis.

\begin{tabular}{|c|c|c|c|}
\hline \multicolumn{4}{|c|}{ Table 3. Benchmark Regression: Average and Conditional Marginal Effects } \\
\hline & \multirow[b]{2}{*}{$\begin{array}{c}\text { Average } \\
\text { Marginal } \\
\text { Effects 1/ } \\
\text { (1) } \\
\end{array}$} & \multicolumn{2}{|c|}{ Marginal Effects } \\
\hline & & $\begin{array}{c}\text { Median LIC } \\
2 / \\
(2) \\
\end{array}$ & $\begin{array}{l}\text { LICs with } \\
\text { weak } \\
\text { fundamentals } \\
\text { 3/ } \\
\text { (3) }\end{array}$ \\
\hline CPIA (t-1) & -0.1244 & -0.1398 & -0.1713 \\
\hline Government balance, (\% of GDP) (t-1) & -0.0092 & -0.0103 & -0.0126 \\
\hline Food supply growth average (cal) & -0.2321 & -0.2609 & -0.3195 \\
\hline Reserve coverage (months of imports) ( $t-1$ ) & -0.0327 & -0.0367 & -0.0449 \\
\hline Export prices percent change & 0.0224 & 0.0252 & 0.0309 \\
\hline Growth in trading partners weighted by lagged exports to GDP & -0.1177 & -0.1323 & -0.1620 \\
\hline Exchange market pressure index & -0.0287 & -0.0323 & -0.0395 \\
\hline \multicolumn{4}{|c|}{$\begin{array}{l}\text { Source: FAO; World Bank; EM-DAT; IMF WEO and author's calculations. } \\
\text { 1/ Marginal effects of a specific covariate on the response probability averaged across the distribution of } \\
\text { covariates in the sample. } \\
\text { 2/ All covariates are set at their median for the full sample. } \\
\text { 3/ Covariates are set at their } 75 \text { th ( } 25 \text { th) percentile if their estimated coefficient is positive (negative). }\end{array}$} \\
\hline
\end{tabular}

Finally, to identify a probability threshold which signals high risk of a food supply crisis for the underlying probit model, we estimate the underlying predicted probabilities of the probit model first. Then, based on these predicted probabilities, we use a loss function minimization approach, following Demirguec-Kunt and Detragiache (1999), to derive the food crisis probability threshold. We give equal weights to Type I errors (missed crises) and Type II errors (false alarms). This results in a probability threshold of 0.19 with Type 1 and Type 2 errors equal to 14 percent and 27 percent, respectively (Table 4). The probit model performs fairly well, with a low Type 1 error and reasonable Type 2 error.

\begin{tabular}{|c|c|c|c|c|}
\hline \multicolumn{5}{|c|}{$\begin{array}{c}\text { Table 4. Predicted Probabilities } \\
\text { (Percentiles) }\end{array}$} \\
\hline & \multicolumn{2}{|c|}{ In sample } & \multicolumn{2}{|c|}{ Out of sample 1/ } \\
\hline & Food & Normal & Food & Normal \\
\hline & Crisis & Episodes & Crisis & Episodes \\
\hline $1 \%$ & 0.07 & 0.00 & 0.03 & 0.00 \\
\hline $5 \%$ & 0.08 & 0.00 & 0.03 & 0.00 \\
\hline $10 \%$ & 0.12 & 0.00 & 0.06 & 0.00 \\
\hline $25 \%$ & 0.21 & 0.04 & 0.10 & 0.03 \\
\hline $50 \%$ & 0.38 & 0.10 & 0.30 & 0.08 \\
\hline $75 \%$ & 0.60 & 0.20 & 0.55 & 0.30 \\
\hline $90 \%$ & 0.83 & 0.42 & 0.88 & 0.63 \\
\hline $95 \%$ & 0.86 & 0.54 & 0.89 & 0.90 \\
\hline $99 \%$ & 0.86 & 0.64 & 0.89 & 0.94 \\
\hline Observations & 28 & 101 & 10 & 35 \\
\hline Type I & & 0.14 & & 0.30 \\
\hline Type II & & 0.27 & & 0.31 \\
\hline Sample probab & & 0.22 & & 0.22 \\
\hline Overall threshol & & 0.19 & & 0.19 \\
\hline
\end{tabular}




\section{Goodness of Fit of Probit Model}

Analyzing the distribution of in-sample and out-of-sample predicted probabilities in case of a food crisis and non-food crisis allows an assessment of the "goodness" of fit of the probit model. Table 4 shows that there is a distinct difference in the distribution for food crisis and non-food crisis episodes. The dispersion of the predicted probabilities in the $[0,1]$ interval indicates that the empirical model is able to distinguish between different states. The more dispersed the predicted probabilities are, the more informative is the underlying model. The median predicted probability for a food crisis is 0.38 against 0.10 in normal times.

To better analyze the goodness of fit, the predictions of the model are tested against out of sample data. To do this, we estimate the model for 1990-2004 and calculate the predicted probabilities for the remainder of the data 2005-2009 (see Table 4). When applying the threshold probability of 0.19 (as estimated for the overall sample), the model identifies correctly seven out of 10 crises. False alarms are given in 31 percent of the non-crisis episodes that is, 11 out of 35 non-crisis episodes were misspecified as a crisis. Admittedly, the performance of the out of sample is slightly worse than the in-sample, which is likely related to the low number of crisis observation.

\section{Robustness Check}

To check the robustness of our results, we test if our model specification holds when we are not restricting the sample to natural disaster shocks only. This means, we estimate if the explanatory variables identified in Table 2 are able to predict a food crisis which could have been caused by anything not only natural disasters. In this robustness test every food decline episode (151) is regressed on the aforementioned variables. Table 2 in the Appendix shows that results remain broadly unchanged in this general specification, as most variables remain significant except for reserves and the exchange market pressure index. This also proves that our results generally hold independent of our definition of natural disasters in Section II B.

\section{Empirical Analysis: Signaling ApProach}

\section{A. Methodology: Signaling Approach}

The first part of the empirical analysis, based on the probit model, focuses on identifying the major determinants of food crises. The probit estimation performs well in identifying a food crisis. In a second step, the results from the probit estimation form the basis for the signaling approach. Using the signaling approach (IMF, 2011), we estimate for each indicator (separately) the threshold which indicates food supply risk. This is done by differentiating between a crisis and non-crisis episode for each indicator. Should one indicator breach this threshold, the model signals upcoming food crisis. An optimal threshold balances Type I (i.e. missing a crisis) and Type II errors (i.e. false alarm). Thus a low threshold results in more false alarms (larger Type II error) while a high threshold increases the probability of missing a crisis (larger Type I error). 
A signaling variable, $s_{i t}$, can be defined as follows:

$s_{i t}= \begin{cases}1, & \text { if } x_{i t-1}>T_{i} \\ 0, & \text { otherwise }\end{cases}$

with $x_{i t-1}$ referring to an indicator variable $i$, which is monotonically increasing with the probability of a crisis. $T_{i}$ represents the threshold value identified for $x_{i t-1}$. In this paper, we use the minimization of the total misclassification error (TME) method to determine the threshold value $T$ for each indicator variable. Using this method, each threshold $T$ can be expressed as the sum of Type I and Type II error:

$T M E(T)=\frac{\text { Missed crisis }(T)}{\text { Total crises }}+\frac{\text { False alarms }(T)}{\text { Total non-crisis }}$.

The optimal threshold, $T^{*}$, is derived by minimizing $T M E(T)$. The overall index is then calculated by weighting each indicator by its predictive power. This is done in two steps. First, variables are grouped into three clusters: (i) overall economy and institutions; (ii) external sector; and (iii) fiscal sector. Each indicator in this cluster is assigned a weight based on its predictive power. Second, each cluster receives a weight based on its predictive power compared to the other clusters. These weighted clusters are summed up to a vulnerability index:

Overall Index ${ }_{i}=\sum_{c} w_{c} \sum_{i} w_{i c} s_{i t}$

where $w_{i c}$ is the weight of each individual indicator $x_{i t-1}$ in cluster $c$, with $w_{c}$ estimated as the weight of the group, and $s_{i t}$ is a dummy variable that takes the value of 1 if the indicator is above (below) the threshold and zero otherwise.

\section{B. Results: Signaling Approach}

The analysis uses 12 variables, based on the results from probit regressions above and a number of variables considered in the literature as main determinants of food supply decline: share of agriculture in total GDP; life expectancy; population growth; government tax revenue and government debt. ${ }^{12}$ Table 5 shows the composition of the food decline vulnerability index (FDVI) and information on performance of individual indicators grouped by the three clusters: overall economy and institutional sector, external sector, and fiscal sector. The overall economy and institutional sector cluster comprise the CPIA index, life expectancy, food supply growth average, agricultural value added, and population growth. The second cluster includes reserves coverage, the EMPI index, and the exogenous shocks to external demand and export prices. The third cluster includes government balance, tax revenues, and public debt. Except for the two exogenous shocks and average food supply, all variables are lagged by one period.

\footnotetext{
12 This approach accommodates differences in data availability across countries and allows for the inclusion of a potentially larger number of vulnerability indicators than the multivariate regression method.
} 
For each indicator, the first two columns in Table 5 show the food crisis and non-food crisis observations. A total of 42 food crisis episodes were found to match with the occurrence of natural disasters. ${ }^{13}$ The third column presents the estimated thresholds followed by the corresponding Type I and Type II errors (columns 4 and 5). The weight of each indicator in the overall FDVI is shown in column 6. The top predictor of food crisis is the overall economy and institutional sector (responsible for more than 40 percent of the index weight). In this sector, food supply average growth has the highest weight followed by life expectancy and agricultural value added. The external sector has a weight of 34 percent and the fiscal sector has a weight of 24 percent. The overall index threshold (0.35) is derived by minimizing an asymmetrically-weighted loss function which puts more weight on Type I errors (missing a crisis).

\begin{tabular}{|c|c|c|c|c|c|c|c|}
\hline \multicolumn{8}{|c|}{ Table 5. Food Decline Vulnerability Index Estimation Results /1 } \\
\hline Variables $1 /$ & $\begin{array}{l}\text { Direction } \\
\text { to be safe }\end{array}$ & Food crisis & $\begin{array}{c}\text { Normal } \\
\text { episodes }\end{array}$ & Thresholds & Type I error & $\begin{array}{l}\text { Type II } \\
\text { error }\end{array}$ & Index weight \\
\hline \multicolumn{8}{|l|}{ Overall economy and institutions } \\
\hline $\mathrm{CPIA}(\mathrm{t}-1)$ & $>$ & 38 & 124 & 2.84 & 0.66 & 0.23 & 0.05 \\
\hline Life expectancy & $>$ & 38 & 134 & 56.59 & 0.26 & 0.48 & 0.13 \\
\hline Food supply growth average (cal) & $>$ & 42 & 128 & 0.28 & 0.38 & 0.31 & 0.16 \\
\hline Agriculture value added (in percent of GDP) (t-1) & $<$ & 37 & 125 & 20.60 & 0.11 & 0.74 & 0.07 \\
\hline Population growth & $>$ & 33 & 126 & 2.72 & 0.39 & 0.54 & 0.03 \\
\hline \multicolumn{8}{|l|}{ External Sector } \\
\hline Reserve coverage (months of imports) ( $\mathrm{t}-1)$ & $>$ & 35 & 120 & 1.95 & 0.49 & 0.28 & 0.11 \\
\hline Growth in trading partners weighted by lagged exports to GDP & $>$ & 36 & 124 & 0.25 & 0.67 & 0.15 & 0.09 \\
\hline Exchange market pressure index & $>$ & 31 & 115 & -0.61 & 0.58 & 0.27 & 0.06 \\
\hline Export prices percent change & $<$ & 35 & 124 & -0.29 & 0.14 & 0.68 & 0.08 \\
\hline \multicolumn{3}{|l|}{ Fiscal Sector } & & & & & 0.24 \\
\hline Government balance (\% of GDP) (t-1) & $>$ & 42 & 133 & -4.03 & 0.45 & 0.34 & 0.09 \\
\hline Government tax revenue (t-1) & $>$ & 28 & 93 & 19.07 & 0.07 & 0.84 & 0.03 \\
\hline Government debt (t-1) & $<$ & 20 & 81 & 74.98 & 0.40 & 0.40 & 0.09 \\
\hline Real government revenue (\% change over 2 yrs) (t-1) & $>$ & 25 & 98 & -11.90 & 0.88 & 0.07 & 0.02 \\
\hline \multicolumn{8}{|l|}{ Fit of the Model } \\
\hline Overall Index threshold & & & & & & & 0.35 \\
\hline Proportion of Crisis Missed & & & & & & & 0.12 \\
\hline Proportion of Non-crisis mis-specified (false alarms) & & & & & & & 0.45 \\
\hline Overall error & & & & & & & 0.37 \\
\hline \multicolumn{8}{|c|}{ 1/ Sample includes 63 PRGT-eligible countries for the time period 1990-2009, including climatic shocks. } \\
\hline $\begin{array}{l}\text { Sources: FAO; World Bank; EM-DAT; and IM } \\
1 \text { / Sample includes } 55 \text { LICs for the time period } \\
\text { episodes (where the post two year -average is n } \\
\text { availability of food supply data until } 2009 \text {. }\end{array}$ & $\begin{array}{l}\text { F, WEO } \\
1990-20 \\
\text { ecessary) }\end{array}$ & $\begin{array}{l}\text { and author } \\
\text { 08. Due to } \\
\text { the estims }\end{array}$ & $\begin{array}{l}\text { 's calcu } \\
\text { the ider } \\
\text { ation per }\end{array}$ & $\begin{array}{l}\text { lations. } \\
\text { atification } \\
\text { iod has to }\end{array}$ & $\begin{array}{l}\text { of food su } \\
\text { stop in } 20\end{array}$ & $\begin{array}{l}\text { pply cri } \\
08 \text { desp }\end{array}$ & $\begin{array}{l}\text { is } \\
\text { te the }\end{array}$ \\
\hline
\end{tabular}

To assess the ability of the overall food decline vulnerability index and its subcomponents to provide early warning signals, we estimate univariate probit regressions for the FDVI (Table 6). Table 6 shows the distribution of the predicted probabilities for the overall index as well for its subcomponents. The predicted probabilities for the overall index are well

\footnotetext{
${ }^{13}$ In the overall sample, 42 food decline episodes were found. However, Table six only reports the crisis episodes which coincide with the data availability of each variable. Therefore, the number of crisis episodes varies for each variable between 20 (for government debt) and 42 observations (for government balance).
} 
distributed; better than any of its sub-components. The more dispersed distribution of the economy and institutions index provides evidence to assigning a higher weight to this cluster. In the same regard, a slightly higher weight should be given to external sector cluster when compared to the fiscal index.

\begin{tabular}{|c|c|c|c|c|c|c|c|c|}
\hline \multicolumn{9}{|c|}{$\begin{array}{c}\text { Table 6. Distribution of Predicted Probabilities: Vulnerability Index Versus Its Sub- } \\
\text { Components }\end{array}$} \\
\hline & \multicolumn{2}{|c|}{ Vulnerability Index } & \multicolumn{2}{|c|}{$\begin{array}{l}\text { Economy and } \\
\text { Institutions Index }\end{array}$} & \multicolumn{2}{|c|}{ External Index } & \multicolumn{2}{|c|}{ Fiscal Index } \\
\hline & Food & Normal & Food & Normal & Food & Normal & Food & Normal \\
\hline & Crisis & Episodes & Crisis & Episodes & Crisis & Episodes & Crisis & Episodes \\
\hline $1 \%$ & 0.02 & 0.02 & 0.05 & 0.05 & 0.10 & 0.10 & 0.15 & 0.15 \\
\hline $5 \%$ & 0.04 & 0.04 & 0.05 & 0.05 & 0.10 & 0.10 & 0.15 & 0.15 \\
\hline $10 \%$ & 0.10 & 0.06 & 0.11 & 0.06 & 0.10 & 0.10 & 0.15 & 0.15 \\
\hline $25 \%$ & 0.23 & 0.08 & 0.21 & 0.11 & 0.22 & 0.16 & 0.18 & 0.15 \\
\hline $50 \%$ & 0.34 & 0.16 & 0.33 & 0.21 & 0.28 & 0.18 & 0.24 & 0.18 \\
\hline $75 \%$ & 0.49 & 0.28 & 0.44 & 0.27 & 0.33 & 0.26 & 0.29 & 0.28 \\
\hline $90 \%$ & 0.57 & 0.40 & 0.49 & 0.41 & 0.44 & 0.33 & 0.41 & 0.29 \\
\hline $95 \%$ & 0.65 & 0.45 & 0.49 & 0.44 & 0.48 & 0.34 & 0.41 & 0.41 \\
\hline $99 \%$ & 0.81 & 0.52 & 0.52 & 0.52 & 0.48 & 0.48 & 0.41 & 0.41 \\
\hline Observations & 42 & 141 & 42 & 141 & 42 & 141 & 42 & 141 \\
\hline
\end{tabular}

\section{Goodness of Fit of Signaling Approach}

Table 7 presents the distribution of food decline vulnerability index for crisis and normal episodes. The predicted vulnerability index for a food supply crisis around the median is 0.51 against 0.33 for normal episodes. Most of the food crisis events ( 75 percent) have a food decline index higher than 0.49 and only 10 percent of food crisis episodes report an index below 0.10. Concerning the evaluation of the in-sample performance, the index correctly calls 88 percent of the food crisis events with an overall model misclassification error (sum of Type 1 and Type 2 error as percent of total observation) of 37 percent. To distinguish between moderate and low probabilities of a food supply crisis, we select another threshold of 0.21. At this threshold, less than 10 percent of food supply crisis are missed while false alarms increase to about 73 percent.

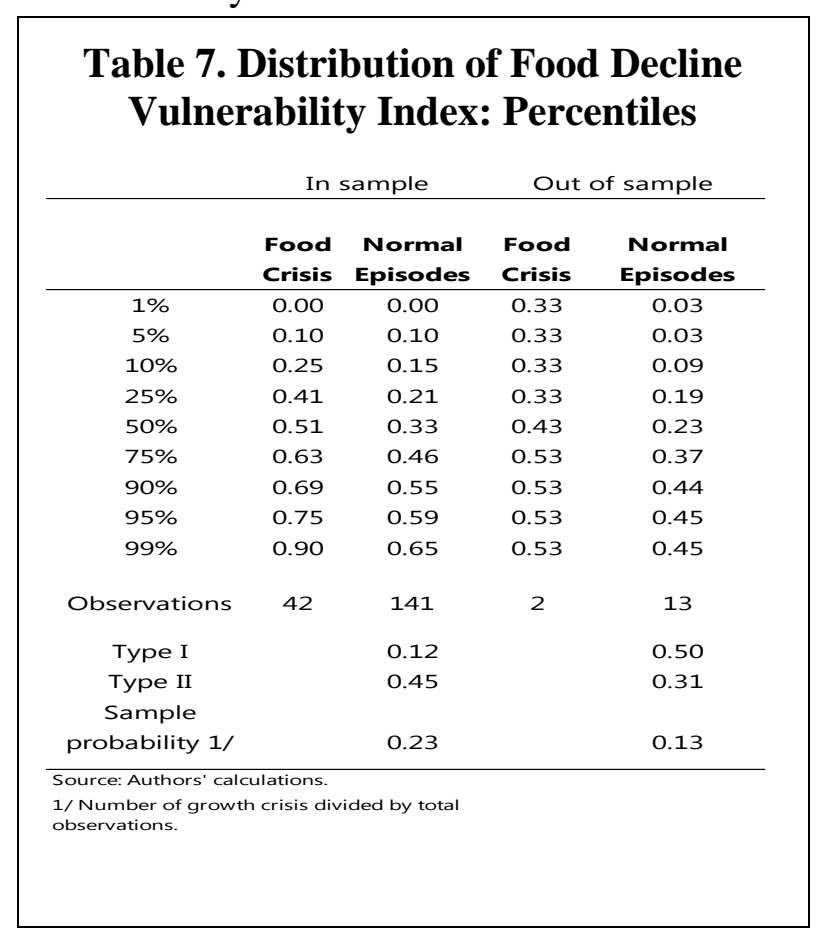




\section{Assessment of Vulnerabilities since 1990s}

Figure 3 shows the development of the FDVI since the 1990s. ${ }^{14}$ As can be seen from the chart, the index increased sharply in 1995 before it declined again in 1997. After that it has steadily increased until 2003 where it reached its peak. As can be seen from Figure 1 in the Appendix, which shows the performance of the underlying variables within the FDVI, the sharp increase in the mid-nineties was mainly caused by high changes in export prices, pressure on the exchange rates and to some extent high fiscal deficits. These three variables together with CPIA and population growth were also driving the steady increase of the FDVI since 1997 until it reached its peak in 2003. During this time, many LICs experienced also an increase in the frequency of natural disasters (see Figure 4). After 2003, with the decline in the frequency of natural disasters, food supply vulnerabilities have receded as well on account of lower vulnerabilities in agricultural production, lower fiscal deficits, higher reserves, and receding pressure on their exchange rates reaching their lowest point in 2013 with a notable outlier in 2009. The outlier in 2009 was caused by a sudden drop in export prices and pressures on the exchange rate.

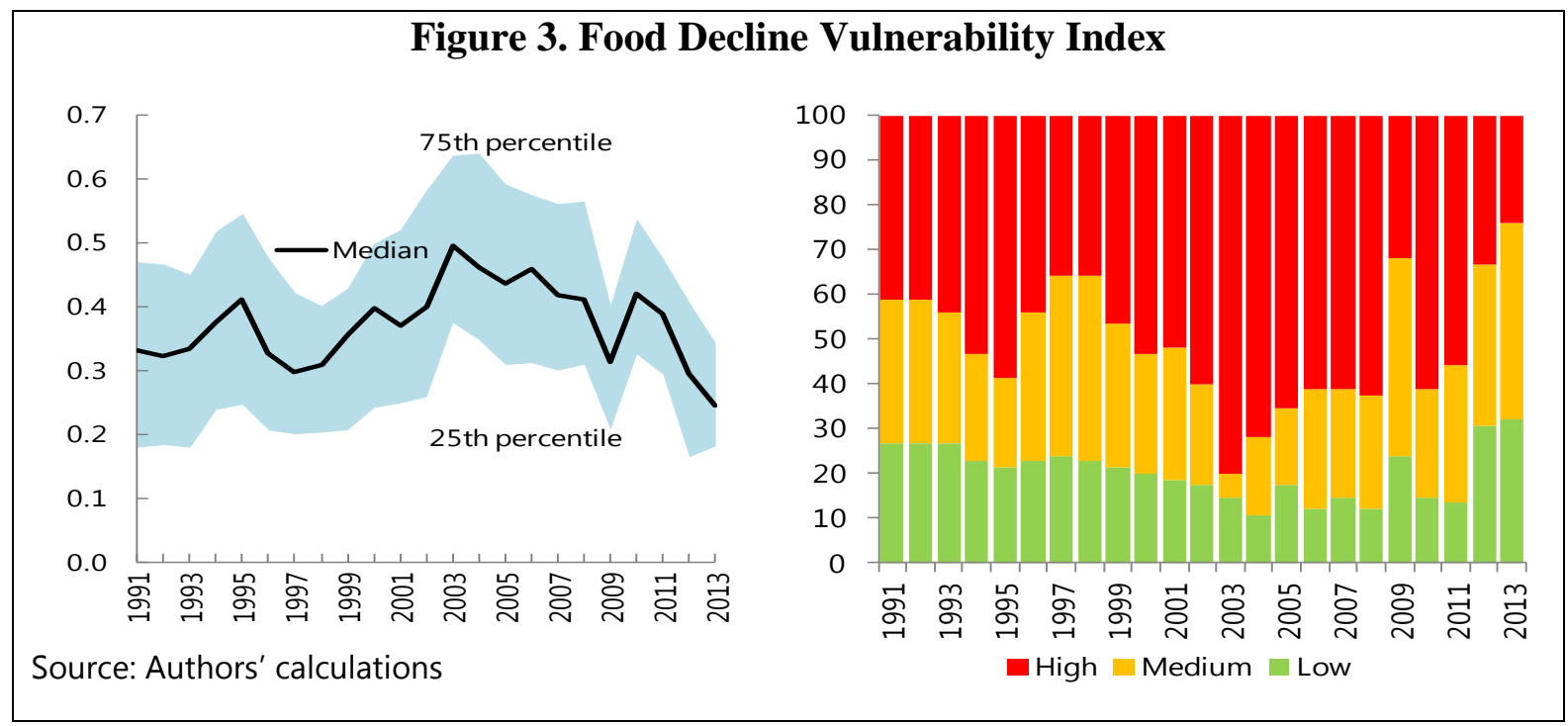

\footnotetext{
${ }^{14}$ We use the overall index threshold 0.35 (see Table 5), which we obtained from minimizing an asymmetrically weighted loss function which puts a higher weight on Type I errors (missing a crisis), to distinguish between high and medium food supply risks. This threshold corresponds to a Type I error of 12 percent. To differentiate between medium and low risk, we select an index threshold from the minimization function which corresponds to a Type I error of 8 percent.
} 


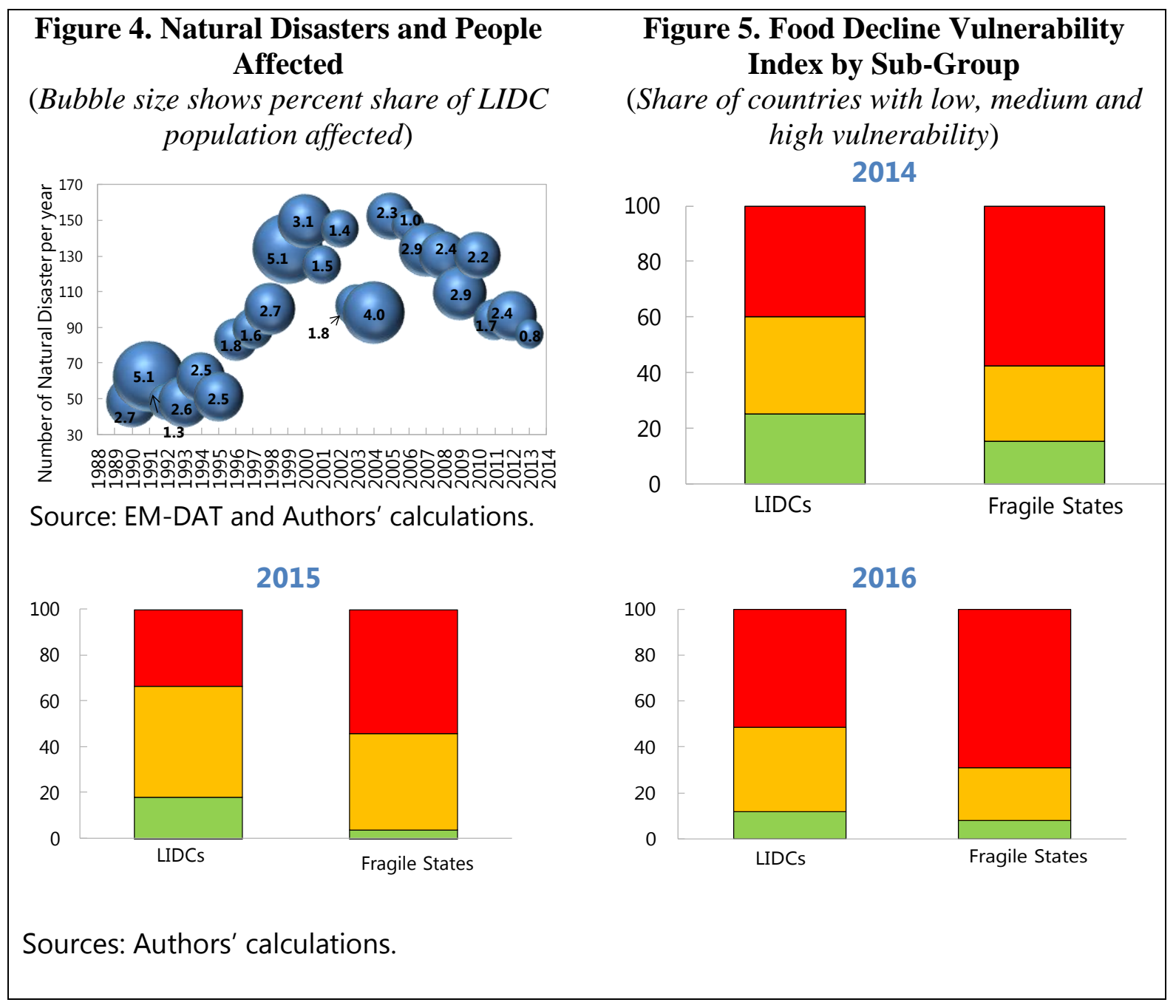

Looking ahead and disaggregating the index in country groups, we see that Fragile States are more prone to a decline in food supply (see Figure 5). While the share of Fragile States with high risk countries is not increasing in 2015, the share of countries with a medium risk rating is edging up. The share of medium risk rated countries is increasing in 2015 partly due to higher vulnerabilities in previously low risk rated countries but also due to a decrease in vulnerabilities in high risk rated countries. For 2016 the FDVI projects a substantial increase in food insecurities with high and medium risk rating increasing across the board.

\section{Conclusions}

The exposure of LICs to natural disasters has a significant impact on food production and food security. An understanding of the interplay between the occurrence and the impact of natural disaster on food crisis and how the existence of macroeconomic buffers could help to mitigate the impact of such shocks is important. This paper fills a very important gap in the literature, by focusing on the potential role that the availability of macroeconomic buffers could play in limiting the occurrence of food crisis associated with natural disasters. We recognize that all potential indicators that could impact on food crisis have not been incorporated, reflecting the dearth of relevant data. 
This paper provides a framework for assessing a country's vulnerability to food crisis in the event of natural disasters. Two complementary approaches (multivariate regression analysis and a univariate signaling approach) have been used to map information from the underlying macroeconomic and institutional to form a composite food crisis vulnerability index. The paper finds that macroeconomic and structural indicators that are crucial for ensuring the resilience of LICs to adverse external shocks are equally important for minimizing the occurrence of food crisis in the event of natural disasters. Results show the probability of experiencing a food crisis increases for countries with weaker institutions and low food supply per capita growth trend. Fragile States are found to be more prone to food crises episodes.

A country's ability to avert a food crisis in the context of a large natural disaster could depend on pre-existing macroeconomic conditions. Aside from this, actions are needed to secure supplementary buffers through insurance schemes, such as self-insurance via contingency reserves, and rapid access to disaster support lines from donors, while also freeing up resources for disaster preparedness. LICs that are particularly vulnerable to natural disasters and food production shocks should seek to lower trade barriers and improve road networks to create a larger regional market and allow a faster and more efficient response to localized food shortages. 


\section{Appendix Table 1. List of Countries in the Sample}

\begin{tabular}{|c|c|c|c|}
\hline & 74 LICs & \multicolumn{2}{|c|}{55 countries used in the regressions } \\
\hline Afghanistan, I.S. of & Mali & Afghanistan, I.S. of & Myanmar \\
\hline Bangladesh & Marshall Islands & Bangladesh & Nicaragua \\
\hline Benin & Mauritania & Benin & Niger \\
\hline Bhutan & Micronesia, Fed. States of & Bhutan & Nigeria \\
\hline Bolivia & Moldova & Bolivia & Papua New Guinea \\
\hline Burkina Faso & Mongolia & Burkina Faso & Rwanda \\
\hline Burundi & Mozambique & Burundi & Senegal \\
\hline Cambodia & Myanmar & Cambodia & Sierra Leone \\
\hline Cameroon & Nepal & Cameroon & Solomon Islands \\
\hline Cape Verde & Nicaragua & Central African Republic & Sudan \\
\hline Central African Republic & Niger & Chad & Tajikistan \\
\hline Chad & Nigeria & Comoros & Tanzania \\
\hline Comoros & Papua New Guinea & Congo, Dem. Rep. of & Togo \\
\hline Congo, Dem. Rep. of & Rwanda & Congo, Republic of & Uganda \\
\hline Congo, Republic of & Samoa & Côte d'Ivoire & Uzbekistan \\
\hline Côte d'Ivoire & São Tomé and Príncipe & Djibouti & Vietnam \\
\hline Djibouti & Senegal & Eritrea & Yemen, Republic of \\
\hline Dominica & Sierra Leone & Ethiopia & Zambia \\
\hline Eritrea & Solomon Islands & Gambia, The & \\
\hline Ethiopia & Somalia & Ghana & \\
\hline Gambia, The & South Sudan & Guinea & \\
\hline Ghana & St. Lucia & Guinea-Bissau & \\
\hline Grenada & St. Vincent and the Grenadines & Haiti & \\
\hline Guinea & Sudan & Honduras & \\
\hline Guinea-Bissau & Tajikistan & Kenya & \\
\hline Guyana & Tanzania & Kyrgyz Republic & \\
\hline Haiti & Timor-Leste, Democratic Republic of & Lao PDR & \\
\hline Honduras & Togo & Lesotho & \\
\hline Kenya & Tonga & Madagascar & \\
\hline Kiribati & Tuvalu & Malawi & \\
\hline Kyrgyz Republic & Uganda & Mali & \\
\hline Lao PDR & Uzbekistan & Marshall Islands & \\
\hline Lesotho & Vanuatu & Mauritania & \\
\hline Liberia & Vietnam & Micronesia, Fed. States of & \\
\hline Madagascar & Yemen, Republic of & Moldova & \\
\hline Malawi & Zambia & Mongolia & \\
\hline Maldives & Zimbabwe & Mozambique & \\
\hline
\end{tabular}




\section{Appendix Table 2. Probability of Food Crisis}

(Correlated Pooled Probit Regression, 1990-2009)

\begin{tabular}{|c|c|c|c|c|}
\hline & $\begin{array}{r}\text { All LICs } \\
(1) \\
\end{array}$ & $\begin{array}{r}\text { Average } \\
\text { marginal } \\
\text { effects } \\
(2) \\
\end{array}$ & $\begin{array}{l}\text { All LICs } \\
\text { (including } \\
\text { natural } \\
\text { disasters) } \\
\text { (3) }\end{array}$ & $\begin{array}{l}\text { All LICs } \\
\text { Logit } \\
(4) \\
\end{array}$ \\
\hline CPIA (t-1) & $\begin{array}{l}-0.257^{\star *} \\
(0.0888)\end{array}$ & $\begin{array}{l}-0.063 \text { ** } \\
(0.0216)\end{array}$ & $\begin{array}{l}-0.259 * * \\
(0.0897)\end{array}$ & $\begin{array}{l}-0.964 * \\
(0.489)\end{array}$ \\
\hline Government balance, & & & & \\
\hline GDP) $(t-1)$ & $\begin{array}{r}-0.0228^{*} \\
(0.0108)\end{array}$ & $\begin{array}{l}-0.006 \text { * } \\
(0.0027)\end{array}$ & $\begin{array}{r}-0.0235^{*} \\
(0.0110)\end{array}$ & $\begin{array}{l}-0.0714^{*} \\
(0.0357)\end{array}$ \\
\hline $\begin{array}{l}\text { Food supply growth } \\
\text { average (cal) }\end{array}$ & $\begin{array}{r}-0.783^{* * *} \\
(0.0708)\end{array}$ & $\begin{array}{l}-0.194^{* * *} \\
(0.0131)\end{array}$ & $\begin{array}{r}-0.784^{* * *} \\
(0.0711)\end{array}$ & $\begin{array}{l}0.180 * \star \star \\
(0.0529)\end{array}$ \\
\hline $\begin{array}{l}\text { Reserve coverage (mon } \\
\text { of imports) (t- } 1 \text { ) }\end{array}$ & $\begin{array}{r}-0.0143 \\
(0.0255)\end{array}$ & $\begin{array}{r}-0.004 \\
(0.0063)\end{array}$ & $\begin{array}{l}-0.0135 \\
(0.0255)\end{array}$ & $\begin{array}{l}-0.970 * \star \\
(0.337)\end{array}$ \\
\hline $\begin{array}{l}\text { Export prices percent } \\
\text { change }\end{array}$ & $\begin{array}{r}0.0195^{*} \\
(0.00901)\end{array}$ & $\begin{array}{r}0.005 \text { * } \\
(0.0022)\end{array}$ & $\begin{array}{r}0.0195^{*} \\
(0.00896)\end{array}$ & $\begin{array}{c}-1.819 * * * \\
(0.409)\end{array}$ \\
\hline $\begin{array}{l}\text { Growth in trading partr } \\
\text { weighted by lagged } \\
\text { exports to GDP }\end{array}$ & $\begin{array}{r}-0.230 * * * \\
(0.0520)\end{array}$ & $\begin{array}{l}-0.057^{* * *} \\
(0.0127)\end{array}$ & $\begin{array}{r}-0.230 * * * \\
(0.0520)\end{array}$ & $\begin{array}{l}-0.272^{*} \\
(0.112)\end{array}$ \\
\hline $\begin{array}{l}\text { Exchange market press } \\
\text { index }\end{array}$ & $\begin{array}{l}-0.0178 \\
(0.0218)\end{array}$ & $\begin{array}{r}-0.004 \\
(0.0054)\end{array}$ & $\begin{array}{l}-0.0185 \\
(0.0219)\end{array}$ & $\begin{array}{l}-0.233^{*} \\
(0.116)\end{array}$ \\
\hline $\begin{array}{l}\text { People affected from } \\
\text { natural disasters (in } \\
\text { percent of population) }\end{array}$ & & & $\begin{array}{l}0.0722 \\
(0.130)\end{array}$ & \\
\hline Constant & $\begin{array}{l}0.617^{*} \\
(0.267)\end{array}$ & & $\begin{array}{l}0.597^{*} \\
(0.269)\end{array}$ & $\begin{array}{l}3.975^{*} \\
(1.784)\end{array}$ \\
\hline Observations & 743 & & 743 & 129 \\
\hline Pseudo R-sq & 0.122 & & 0.122 & 0.261 \\
\hline Number of countries & 47 & & 45 & 47 \\
\hline Food decline episodes & 151 & & 151 & 28 \\
\hline Normal episodes & 592 & & 592 & 101 \\
\hline Wald test (Chi-square) & 171.48 & & 171.48 & 36.72 \\
\hline Sample probability & 0.20 & & 0.20 & 0.22 \\
\hline \multicolumn{5}{|c|}{$\begin{array}{l}\text { Source: FAO; World Bank; EM-DAT; IMF WEO and author's calculations. } \\
\text { Note: Estimated by a correlated pooled probit model with cluster-robust } \\
\text { standard errors. } \\
\text { Significant at } 10 \text { percent *, } 5 \text { percent }{ }^{* *}, 1 \text { percent }{ }^{* *} \text {, standard errors are in } \\
\text { parentheses. }\end{array}$} \\
\hline
\end{tabular}




\begin{tabular}{|c|c|c|c|}
\hline \multicolumn{4}{|c|}{ Appendix Table 3. Variables Used in the Probit Regressions and the Signaling Approach } \\
\hline \multirow[t]{2}{*}{ Sector } & Variables & Description & Source \\
\hline & \multicolumn{3}{|c|}{$\begin{array}{l}\text { Probit Regressions } \\
\end{array}$} \\
\hline \multirow[t]{2}{*}{ Economy and Institutions } & CPIA (t-1) & Lag of country policy and institutions assessment & World Bank \\
\hline & Food supply growth average (cal) & Average growth of food supply in kilo calories & Food and Agriculture Organization \\
\hline Fiscal sector & Government balance, (\% of GDP) (t-1) & Lag of general government balance, in percent of GDP & World Economic Outlook \\
\hline \multirow[t]{8}{*}{ External sector } & Reserve coverage (months of imports) (t-1) & Lag of reserves in months of next's year of imports & World Economic Outlook, International Finance Statistics, Staff Reports \\
\hline & Export prices percent change & Growth in export prices of goods weighted by lagged exports to GDP ratio & World Economic Outlook \\
\hline & Growth in trading partners weighted by lagged exp & o External demand growth in trading partners weighted by lagged exports ( $\mathrm{g}$ & a World Economic Outlook \\
\hline & Exchange market pressure index & Exchange market pressure index & World Economic Outlook \\
\hline & Shock variables & & \\
\hline & Number of affected from natural disasters & Number of people affected from natural disasters excluding number of kille & ff CRED Internatinal Disaster Database, (EM-DAT) \\
\hline & Cost of natural disasters & Cost of natural disasters, in percent of GDP & CRED Internatinal Disaster Database, (EM-DAT) \\
\hline & \multicolumn{3}{|c|}{ Signalling Approach } \\
\hline \multirow[t]{4}{*}{ External sector } & Reserve coverage (months of imports) (t-1) & Lag of reserves in months of next's year of imports & World Economic Outlook, International Finance Statistics, Staff Reports \\
\hline & Exchange market pressure index & Exchange market pressure index & World Economic Outlook \\
\hline & Export prices percent change & Growth in export prices of goods weighted by lagged exports to GDP ratio & World Economic Outlook \\
\hline & Growth in trading partners weighted by lagged exp & oxternal demand growth in trading partners weighted by lagged exports ( $\mathrm{g}$ & a World Economic Outlook \\
\hline \multirow[t]{3}{*}{ Fiscal sector } & Government balance, (\% of GDP) (t-1) & Lag of general government balance, in percent of GDP & World Economic Outlook \\
\hline & Government taxes, (\% of GDP) (t-1) & Lag of general government tax revenue, in percent of GDP & World Economic Outlook \\
\hline & Public debt, (\% of GDP) (t-1) & Lag of general government debt, in percent of GDP & World Economic Outlook \\
\hline \multirow{5}{*}{ Economy and Institutions } & CPIA (t-1) & Lag of country policy and institutions assessment & World Bank \\
\hline & Food supply growth average (cal) & Average growth of food supply in kilo calories & Food and Agriculture Organization \\
\hline & Agriculture value added (in percent of GDP) (t-1) & Lag of agriculture valued added, in percent of GDP & World Development Indicators \\
\hline & Life expectancy (t-1) & Lag of life expectancy at birth, total (years) & World Development Indicators \\
\hline & Population growth (t-1) & Lag of population growth & World Economic Outlook \\
\hline
\end{tabular}




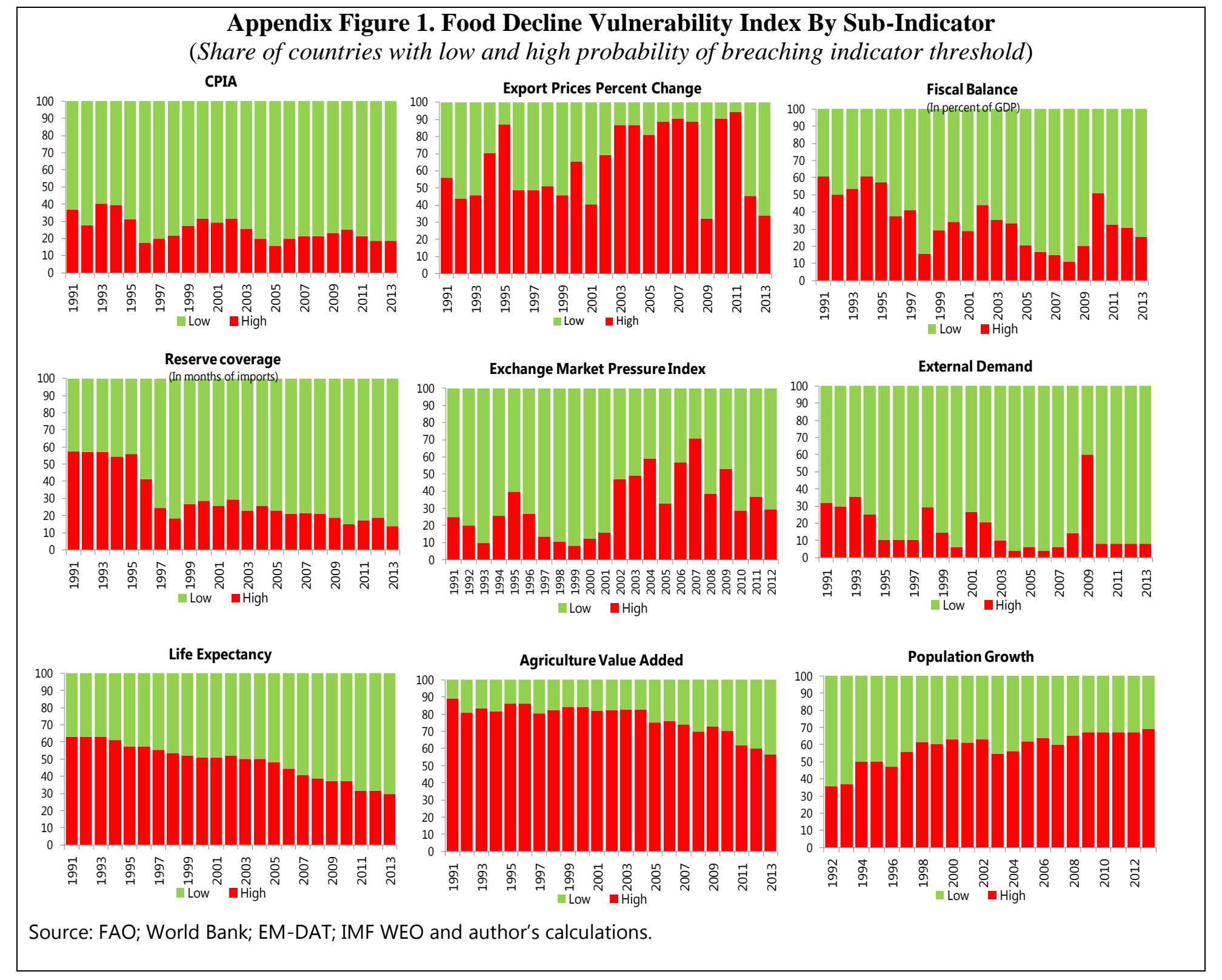




\section{REFERENCES}

Arezki, Rabah, Catherine A. Pattillo, Marc Quintyn, and Min Zhu, 2012, Commodity Price Volatility and Inclusive Growth in Low-Income Countries (Washington: International Monetary Fund).

Burg, Jericho, 2008, “Measuring Populations' Vulnerabilities for Famine and Food Security Interventions: The Case of Ethiopia's Chronic Vulnerability Index," Disasters, Vol. 32, No. 4, pp. 609-30.

Capaldo, Jeronim, Panagiotis Karfakis, Marco Knowles, and Mark Smulders, 2010, “ㅡㅗ Model of Vulnerability to Food Insecurity," Food and Agriculture Organization of the United Nations, ESA Working Paper No. 10-03 (August).

Cafiero, Carlo, 2013, “What Do We Really Know About Food Security?” NBER Working Paper No. 18861 (Cambridge: National Bureau of Economic Research).

Cavallo, Eduardo, Sebastián Galiani, Ilan Noy, and Juan Pantano, 2010, "Catastrophic Natural Disasters and Economic Growth," IDB Working Paper Series No. IDB-WP183 (Washington: Inter-American Development Bank).

Chamberlain, Gary, 1982, “Multivariate Regression Models for Panel Data," Journal of Econometrics, Vol. 18, No. 1, pp. 5-46.

Chambers, Robert, 1989, "Vulnerability, Coping, and Policy," IDS Bulletin, Vol. 20, No. 2, pp. 1-7.

Dabla-Norris, Era, and Yasemin Bal Gündüz, 2012, "Exogenous Shocks and Growth Crises in Low-Income Countries: A Vulnerability Index, " IMF Working Paper No. 12/264 (Washington: International Monetary Fund).

Dabla-Norris, Era, and Yasemin Bal Gündüz, 2014, "Exogenous Shocks and Growth Crises in Low-Income Countries: A Vulnerability Index," World Development, Vol. 59, Issue C, pp 360-78.

Demirgüc-Kunt, Asli, and Enrica Detragiache, 1999, "Monitoring Banking Sector Fragility: A Multivariate Logit Approach," IMF Working Paper No. 99/147 (Washington: International Monetary Fund).

Economist Intelligence Unit, 2013, “Global Food Security Index 2013: An Annual Measure of the State of Global Food Security."

Food and Agriculture Organization, 2015, “The Impact of Natural Hazards and Disasters on Agriculture and Food Security and Nutrition: A Call for Action to Build Resilient Livelihoods." 
Hallegatte, Stéphane, and Valentin Przyluski, 2010, “The Economics of Natural Disasters: Concepts and Methods," World Bank Policy Research Working Paper No. 5507 (Washington: The World Bank).

— , 2011, "Managing Volatility: A Vulnerability Exercise for Low-Income Countries" (Washington).

—_, 2014, "Macroeconomic Developments in Low-income Developing Countries" (Washington).

Laframboise, Nicole, and Boileau Loko, 2012, "Natural Disasters: Mitigating Impact, Managing Risks," IMF Working Paper 12/245 (Washington: International Monetary Fund).

Loayza, Norman, Eduardo Olaberria, Jamele Rigolini, and Luc Christiaensen, 2009, "Natural Disasters and Growth: Going Beyond the Averages," World Bank Policy Research Working Paper No. 4980 (Washington: The World Bank).

Long, Frank, 1978, “The Impact of Natural Disasters on Third World Agriculture: An Exploratory Survey of the Need for Some New Dimensions in Development Planning," American Journal of Economics and Sociology, Vol. 37, Issue 2, pp. 149-63.

Lucas, P. L., and H.B.M. Hilderink, 2004, "The Vulnerability Concept and Its Application to Food Security," National Institute for Public Health and the Environment, Report No. 550015004.

Mundlak, Yair, 1978, "On the Pooling of Time Series and Cross Section Data," Econometrica, Vol. 46, No. 1, pp. 69-85.

Riely, Frank, 2000, “A Comparison of Vulnerability Analysis Methods and Rationale for Their Use in Different Contexts," A FIVIMS Synthesis Document.

Skidmore, Mark, and Hideki Toya, 2005, "Economic Development and the Impacts of Natural Disasters," Working Paper 05-04, UW-Whitewater, Department of Economics.

Sivakumar, Mannava.V.K., 2005, "Impacts of Natural Disasters in Agriculture, Rangeland, and Forestry: An Overview," in M.V.K. Sivakumar, R.P. Motha, and H.P. Das (Eds.) Natural Disasters and Extreme Events in Agriculture, Springer (Berlin, Heidelberg, New York) pp. 1-22.

World Bank, 2014, "Risk and Opportunity: Managing Risk for Development," World Development Report (Washington). , 2011, "Conflict, Security, and Development," World Development Report (Washington). 